\title{
The Influence of HCV Coinfection on Clinical, Immunological and Virological Responses to HAART in HIV-Patients
}

\author{
Ricardo A. Carmo ${ }^{1,2}$, Mark D.C. Guimarães ${ }^{3}$, Alexandre S. Moura ${ }^{2}$, Augusto M. Neiva ${ }^{1}$, Juliana B. Versiani², \\ Letícia V. Lima ${ }^{2}$, Lílian P. Freitas ${ }^{2}$ and Manoel Otávio C. Rocha ${ }^{2}$ \\ ${ }^{1}$ Hemominas Foundation, Belo Horizonte, Brazil; ${ }^{2}$ Department of Tropical Medicine and Infectious Diseases; ${ }^{3}$ Department of Preventive and \\ Social Medicine, Federal University of Minas Gerais; Belo Horizonte, MG, Brazil
}

\begin{abstract}
The potential impact of the hepatitis $\mathrm{C}$ virus (HCV) on clinical, immunological and virological responses to initial highly active antiretroviral therapy (HAART) of patients infected with human immunodeficiency virus (HIV) is important to evaluate due to the high prevalence of HIV-HCV coinfection. A historical cohort study was conducted among $824 \mathrm{HIV}$-infected patients starting HAART at a public referral service in Belo Horizonte, Brazil, to assess the impact of HCV seropositivity on appearance of a new AIDS-defining opportunistic illness, AIDS-related death, suppression of viral load, and an increase in CD4-cell count. A total of 76 patients $(9.2 \%)$ had a positive HCV test, 26 of whom (34.2\%) had a history of intravenous drug use. In multivariate analysis, HCV seropositivity was associated with a smaller $\mathrm{CD} 4-$ cell recovery $(\mathrm{RH}=0.68 ; 95 \% \mathrm{CI}[0.49-0.92]$, but not with progression to a new AIDS-defining opportunistic illness or to AIDS-related death (RH=1.08; 95\% CI [0.66-1.77]), nor to suppression of HIV-1 viral load (RH=0.81; 95\% CI [0.56-1.17]) after starting HAART. These results indicate that although associated with a blunted CD4-cell recovery, HCV coinfection did not affect the morbidity or mortality related to AIDS or the virological response to initial HAART.
\end{abstract}

Key-Words: AIDS, HIV/HCV coinfection, Brazil, antiretroviral therapy, mortality, morbidity.

Coinfection with hepatitis C virus (HCV) is highly prevalent among HIV-1-infected individuals due to shared routes of transmission, with highest rates of HCV-HIV coinfection being found in regions where intravenous drug use (IDU) is more common [1-5].

Before the introduction of highly active antiretroviral therapy (HAART), HCV infection was not a relevant problem for the HIV-1 infected patients. However, as their life expectancy has increased in the last years, with significantly reduced morbidity and mortality associated with HIV-1 infection [6-8], HCV infection has emerged as an important cofactor to be considered in the clinical and immunological progression of HIV-1 disease and the immunological response to HAART [9-11]. This phenomenon has occurred more clearly in the developed world, but was equally experienced by some developing countries, such as Brazil, where HAART has been widely available since 1996 [12].

HIV-1 infection appears to increase the persistence of HCV, the level of HCV RNA, the progression of HCV-related liver disease and the mortality caused by end-stage liver disease [13-22]. However, there are conflicting reports regarding the effect of HCV on the natural history of HIV-1 disease and on the immunological and virological responses to HAART. While in some studies the HCV coinfection was independently

Received on 9 December 2007; revised 10 April 2008.

Address for correspondence: Dr. Ricardo Andrade Carmo. Alameda Ezequiel Dias, 321. Belo Horizonte, MG. Brazil. Zip code: 30130-110. E-mail: ricarmo@uai.com.br. Phone: +55-31-3290-6550. Fax: +5531-3273-0477. This study was partly supported by grants from FAPEMIG (CBS 219896 and CBS 67497), Eduardo de Menezes Hospital and Hemominas Foundation, Minas Gerais State Health Department, Brazil.

The Brazilian Journal of Infectious Diseases 2008;12(3):173-179. (C) 2008 by The Brazilian Journal of Infectious Diseases and Contexto Publishing. All rights reserved. associated with an increased risk of progression to AIDS and death [23-28] and an impaired CD4-cell recovery after receiving HAART [23,25,28-32], other cohort studies did not find any difference [22,33-38]. We aimed at assessing the association between HCV seropositivity and clinical, immunological and virological responses in a Brazilian cohort of HIV-infected patients initiating HAART, where publications regarding HCV coinfection among HIV infected patients are scarce.

\section{Patients and Methods \\ Data Collection and Patients}

This was a retrospective cohort follow-up study conducted at Orestes Diniz Training and Reference Center for Infectious Diseases, Belo Horizonte, Brazil. This is a public universitybased service that provides comprehensive care for HIVinfected patients and it is the largest HIV outpatient referral center in the city, where HAART has been available since 1996. We included all patients above 12 years old with confirmed HIV-1 infection, who had their first clinical visit at the center between January 1, 1996 and June 30, 2001, and initiated HAART between January 1, 1996 and December 31, 2001. HAART was defined as combinations including at least three drugs, with at least one protease inhibitor or one nonnucleoside reverse-transcriptase inhibitor. Patients should have been tested for anti-HCV (EIA-3.0) prior to six months from the first clinic visit and up to two months after the introduction of HAART (time zero). They should also have had at least one follow-up visit after one month following the start of treatment. HIV-infected pregnant women who only received HAART during the gestational period for HIV vertical transmission prophylaxis were excluded. Hemophiliac patients were managed at a different referral center in Belo Horizonte and therefore were not included in the analysis.

Enrollment was independent of HIV disease stage or degree of immunosuppression. Data were collected by means of a 
comprehensive review of patient medical records after approval was given by the institutional review board. Tlymphocyte CD4+ cell count (determined by standard flow cytometry) and viral-load measurement (measured by polymerase chain reaction (PCR) [Amplicor PCR Diagnostic; Hoffman-La Roche] or nucleic acid sequence-based amplification [NucliSens; Organon Technika, Netherlands] with a limit of detection of 400 HIV-1 RNA copies/mL, 80 HIV-1 RNA copies $/ \mathrm{mL}$ or $50 \mathrm{HIV}-1$ RNA copies/mL according to the year of follow up), were routinely performed, for each patient, two to three times per year at the study center. Serologic status for $\mathrm{HCV}$ was routinely performed for individuals considered to be at high risk (i.e., injection drug users [IDU], recipients of blood products) and for those with abnormal liver enzymes.

The database used for the analysis included information recorded up to December 30, 2002. None of the patients received treatment for HCV infection during the period of study.

\section{Outcomes}

The primary endpoint was progression to a new AIDSdefining opportunistic illness, according to the US Centers for Disease Control and Prevention (CDC) 1993 revised classification system [39], or AIDS-related death. Information on death was obtained from hospital records as well as the Brazilian Mortality Information System, and coded according to the ICD-10. Secondary endpoints were (i) suppression of viral load to below $400 \mathrm{HIV}-1$ RNA copies/mL, and (ii) an increase in CD4-cell count of more than 50 cells $/ \mathrm{mL}$ after starting HAART.

\section{Variables}

Characteristics at the start of HAART (baseline) were studied as potential covariates: age, gender, race, birthplace, place of residence, marital status, formal education, risk factor for acquisition of HIV-1/HCV infections, current HBV infection (reactive anti-HBc-IgG and reactive HBsAg), former HBV infection (reactive anti-HBc-IgG and non-reactive HBsAg), schistosomiasis (past history or presence at baseline), registered alcoholism (alcohol abuse), long-term use (more than a month) of any non-antiretroviral hepatotoxic drug, HIV-1 disease stage (AIDS/no AIDS, according to the CDC 1993 revised classification system[39]), liver-related clinical events (e.g. jaundice, ascites, gynaecomastia, spider naevi, cirrhosis) and use of antiretroviral therapy before HAART. Additional variables analyzed included: HIV-1 disease stage (AIDS/no AIDS) at the last follow-up visit, type of HAART (with or without protease inhibitor), HIV-1 treatment change (any modification in the regimen after the start of HAART), poor adherence to HAART (any chart registering), and hepatotoxicity induced by HAART (defined as an alanine aminotransferase [ALT] elevation $>1.5$ times the upper limit of normal).

\section{Statistical Analysis}

The prevalence rate of HIV-HCV seropositivity with 95\% confidence interval (95\% CI) was estimated. Baseline characteristics were compared according to HCV exposure serostatus using $\chi^{2}$, Fisher's and Student's t tests. Time to clinical, virological or immunological endpoints was measured from the start of HAART. Patients who were lost to follow-up were censored on the date of their last documented clinic visit or on the date of non-AIDS related deaths. The rates of the primary and secondary endpoints were estimated by dividing the number of patients developing the event by the number of person-years at risk. Cox proportional hazard models were used to estimate the crude and adjusted relative hazard (RHs) with $95 \%$ CI. Variables reaching statistical significance at the 0.20 level in univariate analyses were included in the final multivariate regressions using manual stepwise procedures. Assumptions of the Cox proportional hazard analysis were assessed by checking the parallelism of the log-log survival curve.

\section{Results \\ Demographic Characteristics, Seroprevalence, and Baseline Assessment}

Of 2831 HIV-patients aged over 12 years with their first visit to the Orestes Diniz Center between January 1, 1996 and June 30, 2001, 1681 individuals (59.4\%) began HAART between January 1, 1996 and December 31, 2001, 1516 (53.5\%) also had at least one follow-up visit more than one month after the start of treatment; and 827 (29.2\%) were tested for anti-HCV (EIA-3.0) prior to six months from the first clinic visit and, necessarily, before the introduction of HAART (time zero) or until two months after it. Three (0.1\%) pregnant women with HAART use only during pregnancy were excluded from the study. Thus, 824 (29.1\%) HIV-patients were eligible for this analysis. Patients excluded from analysis were similar to those included with regard to age $(\mathrm{p}=0.172)$, gender $(\mathrm{p}=0.892)$, risk factor for acquisition of HIV/HCV ( $\mathrm{p}=0.388)$ and HIV disease stage $(p=0.064)$. The exception was the prevalence of antiHCV, which was lower among the analyzed population $(9.2 \%$ vs. $11.3 \%, \mathrm{p}=0.009$ ). This difference could be attributed to the very strict inclusion criteria of the study which aimed at reducing the time between diagnosis of $\mathrm{HIV}$ and $\mathrm{HCV}$ infections and to minimize bias due to unknown duration of infection.

Baseline characteristics were compared according to prevalent anti-HCV status among the eligible population and are summarized in Table 1. HCV-infected patients were more likely to be intravenous drug users $(\mathrm{p}<0.001)$, to have tested positive for the hepatitis $B$ antibody (anti-HBc-IgG [ $\mathrm{p}=0.002]$ ), and to have had a history of alcoholism ( $\mathrm{p}=0.049)$, liver-related clinical events $(\mathrm{p}=0.010)$ and/or previous use of non-HAART antiretroviral drugs $(\mathrm{p}<0.001)$.

\section{HIV-1 Disease Progression and Survival}

The median time of observation for the primary endpoint was 776 days (range, 7 - 2067 days). A total of 151 patients (18.3\%) had a new AIDS event, and 72 patients (8.7\%) died, with 65 deaths (90.3\%) caused by AIDS. Only two deaths (2.8\%) were related to end-stage liver disease. Tuberculosis

www.bjid.com.br 
$(n=36)$, pneumocystosis $(n=28)$, toxoplasmosis $(n=19)$, oesophageal candidiasis $(n=17)$, cytomegalovirus disease $(n=10)$, intestinal cryptosporidiosis $(n=8)$, Kaposi's sarcoma $(n=7)$, cryptococcosis $(n=4)$, and isosporiasis $(n=3)$ were the most common opportunistic illnesses observed. Thus, considering that 183 patients met the primary endpoint criteria (some of them had a new AIDS event and died), the overall cumulative incidence was $22.2 \%$ and the incidence rate was $0.27 / 1000$ person-days.

Although in univariate analysis HCV seropositivity was associated with the primary endpoint, with a relative hazard of 1.71 (95\% CI=1.12-2.60; $\mathrm{p}=0.013)$, multivariate Cox regression model did not confirm the independent association between HCV and progression to a new AIDS-defining opportunistic illness or death caused by AIDS (RH=1.08 [95\% $\mathrm{CI}=0.66-1.77 ; \mathrm{p}=0.767])$. The independent predictors of the primary endpoint were: HIV-1 disease stage (AIDS) before HAART ( $p=0.001$ ); long-term use (more than a month) of any non-antiretroviral hepatotoxic drug $(\mathrm{p}<0.001)$; HIV-1 treatment change $(p=0.006)$; hepatotoxicity induced by HAART $(p=0.006)$; and poor adherence to HAART $(p=0.034)$. Suppression of viral load below 400 HIV-1 RNA copies/mL $(\mathrm{p}<0.001)$ and increase in CD4-cell count of more than 50 cells/ $\mathrm{mL}$ after the start of HAART $(\mathrm{p}=0.021)$ were independent negative predictors of the development of a new AIDSdefining opportunistic illness or death caused by AIDS after HAART (Table 2).

\section{Virological and Immunological Responses to HAART}

Regarding the virological endpoint, it was possible to study 797 patients (96.7\%), with a median time of observation of 301 days (range, 30 - 2062 days). A total of 486 achieved a viral load below 400 HIV-1 RNA copies/mL after the start of HAART, with an overall cumulative incidence of $61.0 \%$ and incidence rate of 1.19/1000 person-days.

In univariate analysis there was a negative association between HCV seropositivity and the probability of reaching the virological endpoint $(\mathrm{RH}=0.62$ [95\% $\mathrm{CI}=0.44-0.88$; $\mathrm{p}=0.007]$ ), but it did not reach statistical significance after multivariate analysis $(\mathrm{RH}=0.81$ [0.56-1.17; $\mathrm{p}=0.266])$. The independent predictors for reaching HIV-1 RNA levels less than 400 copies/mL after the start of HAART were: an increase in CD4-cell count of more than 50 cells/mL after the start of HAART $(\mathrm{p}<0.001)$ and the use of HAART with protease inhibitor $(p<0.001)$. Poor adherence to HAART $(p<0.001)$, HIV1 treatment change $(\mathrm{p}<0.001)$ and the use of antiretroviral therapy before HAART ( $p=0.007$ ) were independent negative predictors of the virological response (Table 2).

As far as the immunological response was concerned, 753 patients (91.4\%) were available for analysis, with a median time of observation of 155 days (range, 12 - 1960 days). A total of 611 patients had an increase in CD4-cell count of more than 50 cells/mL after the start of HAART, with an overall cumulative incidence of $81.1 \%$ and incidence rate of 2.91/1000 persondays.
In the univariate analysis, the relative hazard of increasing CD4-cell counts by at least 50 cells/mL after the start of HAART was 0.57 (95\% CI=0.42-0.78; $\mathrm{p}<0.001$ ) for HCV-seropositive patients, which was confirmed by multivariate analysis ( $\mathrm{RH}=0.68 ; 95 \% \mathrm{CI}=0.49-0.92 ; \mathrm{p}=0.015$ ) (Table 2). This demonstrates that HCV seropositivity as well as HIV-1 treatment change $(\mathrm{p}=0.029)$ and use of antiretroviral therapy before HAART $(\mathrm{p}=0.039)$ were independently associated with a smaller increase in CD4-cell count after the start of HAART, while suppression of viral load below 400 HIV-1 RNA copies/ $\mathrm{mL}(\mathrm{p}<0.001)$ was an independent predictor of better immunologic response.

\section{Discussion}

Because HIV and HCV share transmission routes, dual infection is common, becoming a widespread problem in the world, including Brazil [1-3,40]. There are several reports regarding the effect of $\mathrm{HCV}$ on the natural history of HIV-1 infection in the developed world, where the availability of HAART is common and has changed the natural history of HIV-1 infection. In developing countries, such as Brazil, where HAART has been equally accessible since 1996, there are no published studies regarding the impact of HCV coinfection among HIV-patients on HAART. Understanding the impact of HCV coinfection on morbidity and mortality of HIV-1 infection is essential to optimize the management of the disease, especially in countries with poor healthcare resources. In this large cohort of Brazilian HIV-infected patients initiating HAART, we found a lower prevalence of HCV-coinfection (9.2\%) compared with other North American and European studies $[1,3,4,23]$. This low prevalence can be partially explained by the fact that hemophiliac HIV-patients were referred to another service. In addition, there was a small proportion of IDU (5.2\%) in this cohort (60.5\% of them coinfected), similar to the characteristics of the AIDS epidemic in Brazil, where HIV infection acquired through drug injection is less prevalent than in developed countries. As expected, there were significant positive associations between $\mathrm{HCV}$ seropositivity and: a) former HBV infection (reactive anti-HBcIgG alone), probably due to similar transmission routes; and b) liver-related clinical events, as a consequence of the natural history of the HCV infection.

After adjusting for potentially confounding variables, the analysis of this cohort showed no evidence that HCV coinfection hastens progression of HIV-1 disease or substantially alters the virological response to HAART. During a median follow-up of 776 days, HCV-seropositive HIV-1infected patients did not show an increased risk of progression to new AIDS-defining clinical events or death caused by AIDS after the introduction of HAART. These findings are supported by other large studies [22,33-38] conducted in the HAART era, showing similar risks of HIV-1 disease progression in populations with or without $\mathrm{HCV}$ coinfection. However, this is still controversial, with cohort differences like variability in the time intervals employed for modeling 
Table 1. Prevalence of anti-HCV (EIA-3.0) seropositivity according to selected characteristics among 824 HIV-patients starting HAART (baseline).

\begin{tabular}{|c|c|c|c|}
\hline Characteristics & $\begin{array}{c}\text { Total } \\
\text { (n) }\end{array}$ & $\begin{array}{l}\text { HCV+ } \\
\text { n (\%) }\end{array}$ & p-value \\
\hline \multicolumn{4}{|l|}{ Age } \\
\hline$\geq 35$ years & 380 & $38(10.0)$ & \multirow[t]{2}{*}{0.554} \\
\hline$<35$ years & 444 & $38(8.6)$ & \\
\hline \multicolumn{4}{|l|}{ Sex } \\
\hline Male & 530 & $52(9.8)$ & \multirow[t]{2}{*}{0.511} \\
\hline Female & 294 & $24(8.2)$ & \\
\hline \multicolumn{4}{|l|}{ Race } \\
\hline Non-white & 369 & $36(9.8)$ & \multirow[t]{2}{*}{0.589} \\
\hline White & 417 & $35(8.4)$ & \\
\hline \multicolumn{4}{|l|}{ Marital Status } \\
\hline Single & 426 & $39(9.2)$ & \multirow[t]{2}{*}{0.997} \\
\hline Not-single & 394 & $37(9.4)$ & \\
\hline \multicolumn{4}{|l|}{ Birthplace } \\
\hline Belo Horizonte (MA) & 351 & $40(11.4)$ & \multirow[t]{2}{*}{0.083} \\
\hline Other cities & 473 & $36(7.6)$ & \\
\hline \multicolumn{4}{|l|}{ Residence Place } \\
\hline Belo Horizonte (MA) & 701 & $64(9.1)$ & \multirow[t]{2}{*}{0.958} \\
\hline Other cities & 123 & $12(9.8)$ & \\
\hline \multicolumn{4}{|l|}{ Education } \\
\hline$\leq 8$ years & 509 & $53(10.4)$ & \multirow[t]{2}{*}{0.197} \\
\hline$>8$ years & 297 & $22(7.4)$ & \\
\hline \multicolumn{4}{|c|}{ Behavior/source of HIV/HCV infection } \\
\hline IDU & 43 & $26(60.5)$ & $<0.001$ \\
\hline Transfusion¥ & 77 & $8(10.4)$ & 0.406 \\
\hline MSM & 257 & $11(4.3)$ & \multirow[t]{2}{*}{0.205} \\
\hline Heterosexual and other & 447 & $31(6.9)$ & \\
\hline \multicolumn{4}{|l|}{ HBsAg } \\
\hline Positive & 41 & $3(7.3)$ & \multirow[t]{2}{*}{$0.466^{\mathrm{f}}$} \\
\hline Negative & 783 & $73(9.3)$ & \\
\hline \multicolumn{4}{|l|}{ Anti-HBc (IgG or total) } \\
\hline Positive & 277 & 38 (13.7) & \multirow[t]{2}{*}{0.002} \\
\hline Negative & 531 & $36(6.8)$ & \\
\hline \multicolumn{4}{|c|}{ Schistosomiasis (former or active) } \\
\hline Yes & 76 & $8(10.5)$ & \multirow[t]{2}{*}{0.838} \\
\hline No & 748 & $68(9.1)$ & \\
\hline Alcoholism & & & \\
\hline Yes & 126 & $18(14.3)$ & 0.049 \\
\hline No & 698 & $58(8.3)$ & \\
\hline Hepatotoxic drug use ( $>30$ & & & \\
\hline Yes & 234 & 24 (10.3) & 0.609 \\
\hline No & 590 & $52(8.8)$ & \\
\hline HIV disease stage (CDC-19 & & & \\
\hline AIDS & 551 & $24(8.8)$ & 0.862 \\
\hline Not-AIDS & 273 & $52(9.4)$ & \\
\hline Liver-related clinical events & & & \\
\hline Yes & 28 & $7(25.0)$ & $0.010^{f}$ \\
\hline No & 796 & $69(8.7)$ & \\
\hline Previous use of anti-retrovi & & & \\
\hline Yes & 381 & 50 (13.1) & $<0.001$ \\
\hline No & 443 & $26(5.9)$ & \\
\hline
\end{tabular}

HAART=highly active antiretroviral therapy; MA=metropolitan area; CDC=Centers for Disease Control and PreventionAtlanta-USA; IDU=intravenous drug users; MSM=men who have sex with men. f=Fisher test. $¥=$ hemophiliacs excluded. 
Table 2. Multivariate Cox's proportional hazard regression models showing significant independent predictors according to different endpoints.

\begin{tabular}{|c|c|c|}
\hline Endpoints/Variables & $\begin{array}{l}\text { Relative hazard } \\
\text { (95\% CI) }\end{array}$ & p-value \\
\hline \multicolumn{3}{|c|}{ AIDS-defining opportunistic illness or death caused by AIDS (n=824) } \\
\hline \multicolumn{3}{|c|}{ HIV disease stage (AIDS) before HAART } \\
\hline AIDS & $2.33(1.41-3.86)$ & 0.001 \\
\hline Not-AIDS & 1.0 & \\
\hline \multicolumn{3}{|c|}{ Long-term use (more than a month) of any non-antiretroviral hepatotoxic drug } \\
\hline Yes & $1.98(1.41-2.77)$ & $<0.001$ \\
\hline No & 1.0 & \\
\hline \multicolumn{3}{|c|}{ HIV-1 treatment change } \\
\hline Yes & $1.82(1.18-2.79)$ & 0.006 \\
\hline No & 1.0 & \\
\hline \multicolumn{3}{|c|}{ Hepatotoxicity induced by HAART } \\
\hline Yes & $1.66(1.15-2.38)$ & 0.006 \\
\hline No & 1.0 & \\
\hline \multicolumn{3}{|c|}{ Poor adherence to HAART } \\
\hline Yes & $1.44(1.03-2.03)$ & 0.034 \\
\hline No & 1.0 & \\
\hline \multicolumn{3}{|c|}{ Suppression of viral load below 400 HIV-1 RNA copies/mL } \\
\hline Yes & $0.45(0.31-0.66)$ & $<0.001$ \\
\hline No & 1.0 & \\
\hline \multicolumn{3}{|c|}{ Increase in CD -cell count of more than 50 cells/mL after HAART } \\
\hline Yes $-4-2$ & $0.64(0.43-0.93)$ & 0.021 \\
\hline \multicolumn{3}{|c|}{ No 1.0} \\
\hline \multicolumn{3}{|c|}{ Suppression of viral load below 400 HIV-1 RNA copies/mL after HAART ( $\mathrm{n}=797$ ) } \\
\hline \multicolumn{3}{|c|}{ Increase in $\mathrm{CD}_{4}$-cell count of more than 50 cells/mL after HAART } \\
\hline Yes $\quad 4$ - & $2.57(1.82-3.66)$ & $<0.001$ \\
\hline No & 1.0 & \\
\hline \multicolumn{3}{|c|}{ Use of HAART with protease inhibitor } \\
\hline Yes & $1.55(1.23-1.94)$ & $<0.001$ \\
\hline No & 1.0 & \\
\hline \multicolumn{3}{|c|}{ Poor adherence to HAART } \\
\hline Yes & $0.47(0.38-0.58)$ & $<0.001$ \\
\hline No & 1.0 & \\
\hline \multicolumn{3}{|c|}{ HIV-1 treatment change } \\
\hline Yes & $0.60(0.48-0.76)$ & $<0.001$ \\
\hline No & 1.0 & \\
\hline \multicolumn{3}{|c|}{ Use of antiretroviral therapy before HAART } \\
\hline Yes & $0.77(0.64-0.93)$ & 0.007 \\
\hline No & 1.0 & \\
\hline \multicolumn{3}{|c|}{ Increase in $\mathrm{CD}_{4}$-cell count of more than 50 cells/mL after HAART $(\mathrm{n}=753$ ) } \\
\hline \multicolumn{3}{|c|}{ Suppression of viral load below 400 HIV-1 RNA copies/mL } \\
\hline Yes & $1.81(1.51-2.17)$ & $<0.001$ \\
\hline No & 1.0 & \\
\hline \multicolumn{3}{|c|}{ Use of antiretroviral therapy before HAART } \\
\hline Yes & $0.84(0.71-0.99)$ & 0.039 \\
\hline No & 1.0 & \\
\hline \multicolumn{3}{|c|}{ HIV-1 treatment change } \\
\hline Yes & $0.83(0.71-0.98)$ & 0.029 \\
\hline No & 1.0 & \\
\hline \multicolumn{3}{|c|}{ Anti-HCV (EIA-3.0) } \\
\hline Positive & $0.68(0.49-0.92)$ & 0.015 \\
\hline Negative & 1.0 & \\
\hline
\end{tabular}

HAART=highly active antiretroviral therapy; CI=confidence interval. 
and failure to correct for important confounding variables, such as active IDU (poorly represented in this study) and adherence to HAART, potentially contributing to these different results. Poor adherence to HAART, especially, is a serious problem in HIV-1 infected patients, mainly in those HCV coinfected [41] and those initiating therapy [42], directly affecting the clinical and the laboratorial outcomes of HAART use. It is possible that studies with longer duration of followup are needed to observe more significant differences in survival duration between HIV-patients using HAART with and without HCV coinfection.

Conversely, the results reported herein indicate that Tlymphocyte CD4+ cell recovery after HAART was delayed in HCV/HIV-coinfected patients. The mechanisms by which HCVinfection might lead to impaired CD4-cell recovery after starting HAART are not well understood. The state of permanent immune activation provided by chronic HCV infection might act deleteriously in HIV-patients, favoring HIV-1 transcription within infected cells and the more rapid destruction of CD4+ Tlymphocytes [43]. In addition, HCV infection of immune cells should be considered as a potential mechanism leading to lower proliferation of CD4-cells [44-45]. Once again the differences in this recovery might be due to some confounding factors, such as poor adherence to HAART [32].

Finally, our findings should be interpreted with caution considering that this study was based on chart data collection only; HCV antibody positivity was the only marker used for HCV infection; and HIV and HCV seroconversion dates were unknown, with possible systematic differences in the duration of both infections. To minimize this last bias, and considering that the majority of the patients on their first clinic visit at the service had had a recent HIV-infection diagnosis, we only included in this cohort HIV-patients who were tested for antiHCV prior to six months after the first clinic visit and, necessarily, before the introduction of HAART or until two months after it. These very rigorous selection criteria were the main reason for exclusion of HIV-infected patients with HCV coinfection and the significant difference between participants and nonparticipant patients according to HCV seropositivity.

In conclusion, in our analysis HCV seropositivity was not associated with an increased risk of progression to a new AIDS-defining opportunistic illness or death caused by AIDS in these Brazilian HIV-1 patients after beginning HAART. However, it was associated with a consistently reduced recovery of CD4 cells over time, without affecting the antiviral activity of HIV-1 therapy. These findings may be important to better understand the impact of HCV coinfection on the HIVpatients in the HAART era, especially in the developing world. Further effects of HCV infection on HIV-1 disease progression and on responses to HAART require additional studies.

\section{Acknowledgements}

The authors would like to acknowledge the colleagues who have substantially contributed to the performance of this study: Alexandre M. Silva, Cristiano V. Ribeiro, Marcela
M. Fonseca, Vivian S. Soares (Department of Tropical Medicine and Infectious Diseases, Federal University of Minas Gerais), Palmira de F. Bonolo, Lorenza N. Campos (Department of Preventive and Social Medicine, Federal University of Minas Gerais), Virgílio V. Neto and Jacqueline G. F. Oliveira (Orestes Diniz Training and Reference Center for Infectious Diseases, Belo Horizonte City Health Department).

\section{References}

1. Alter M., Kruszon-Moran D., Nainan O., et al. The prevalence of hepatitis C virus infection in the United States, 1988 through 1994. New Engl J Med 1999;341:556-62.

2. Mendes-Corrêa M., Barone A., Guastini C. Hepatitis C virus seroprevalence and risk factors among patients with HIV infection. Rev Inst Med Trop São Paulo 2001;43:15-9.

3. Sherman K., Rouster S., Chung R., Rajicic N. Hepatitis C virus prevalence among patients infected with Human Immunodeficiency Virus: a cross-sectional analysis of the US Adult AIDS Clinical Trials Group. Clin Infect Dis 2002;34:831-7.

4. Roca B., Suarez I., Gonzalez J., et al. Hepatitis C virus and human immunodeficiency virus coinfection in Spain. J Infect 2003;47: 117-24.

5. Lumbreras B., Jarrín I., del Amo J., et al. Impact of hepatitis C infection on long-term mortality of injecting drug users from 1990 to 2002: differences before and after HAART. AIDS 2006;20:111-6.

6. Detels R., Muñoz A., McFarlane G., et al. Effectiveness of potent antiretroviral therapy on time to AIDS and death in men with known HIV infection duration. JAMA 1998;280:1497-503.

7. Egger M., May M., Chêne G., et al. Prognosis of HIV-1-infected patients starting highly active antiretroviral therapy: a collaborative analysis of prospective studies. Lancet 2002;360:119-29.

8. Mocroft A., Ledergerber B., Katlama C., et al. Decline in the AIDS and death rates in the EuroSIDA study: an observational study. Lancet 2003;362:22-9.

9. Soriano V., Sulkowski M., Bergin C., et al. Care of patients with chronic hepatitis $\mathrm{C}$ and HIV co-infection: recommendations from the HIV-HCV International Panel. AIDS 2002;16:813-28.

10. Braitstein P., Palepu A., Dieterich D., et al. Special considerations in the initiation and management of antiretroviral therapy in individuals coinfected with HIV and hepatitis C. AIDS 2004;18:2221-34.

11. Alberti A., Clumeck N., Collins S., et al. Short statement of the first European consensus conference on the treatment of chronic hepatitis B and C in HIV co-infected patients. J Hepatol 2005; 42:615-24.

12. Marins J., Jamal L., Chen S., et al. Dramatic improvement in survival among adult Brazilian AIDS patients. AIDS 2003; 17:1675-82.

13. Eyster M., Diamondstone L., Lien J., et al. Natural history of hepatitis $C$ virus infection in multitransfused hemophiliacs: effect of coinfection with human immunodeficiency virus. J Acquir Immune Defic Syndr 1993;6:602-10.

14. Eyster M., Fried M., Di Bisceglie A., Goedert J. Increasing hepatitis C virus RNA levels in hemophiliacs: relationship to human immunodeficiency virus infection and liver disease. Multicenter Hemophilia Cohort Study. Blood 1994;84:1020-3.

15. Rockstroh J., Spengler U., Sudhop T., et al. Immunossupression may lead to progression of hepatitis $\mathrm{C}$ virus-associated liver disease in hemophiliacs coinfected with HIV. Am J Gastroenterol 1996;91:2563-8.

16. Soriano V., Garcia-Samaniego J., Valencia E., et al. Impact of chronic liver disease due to hepatitis viruses as cause of hospital admission and death in HIV-infected drug users. Eur J Epidemiol 1999; $15: 1-4$. 
17. Lesens O., Deschênes M., Steben M., et al. Hepatitis C virus is related to progressive liver disease in human immunodeficiency virus-positive hemophiliacs and should be treated as an opportunistic infection. J Infect Dis 1999;179:1254-8.

18. Bica I., McGovern B., Dhar R., et al. Increasing mortality due to end-stage liver disease in patients with human immunodeficiency virus infection. Clin Infec Dis 2001;32:492-7.

19. Monga H., Rodriguez-Barradas M., Breaux K. et al. Hepatitis C virus infection-related morbidity and mortality among patients with human immunodeficiency virus infection. Clin Infect Dis 2001;33:240-7.

20. Graham C., Baden L., Yu E., et al. Influence of human immunodeficiency virus infection on the course of hepatitis $\mathrm{C}$ virus infection: a meta-analysis. Clin Infect Dis 2001;33:562-9.

21. Pineda J., Romero-Gómez M., Díaz-García F., et al. HIV coinfection shortens the survival of patients with hepatitis $C$ virus-related decompensated cirrhosis. Hepatology 2005;41:779-89.

22. Rockstroh J., Mocroft A., Soriano V., et al. Influence of hepatitis C virus infection on HIV-1 disease progression and response to highly active antiretroviral therapy. J Infect Dis 2005;192:992-1002.

23. Greub G., Ledergerber B., Battegay M., et al. Clinical progression, survival, and immune recovery during antiretroviral therapy in patients with HIV-1 and hepatitis C virus coinfection: the Swiss HIV Cohort Study. Lancet 2000;356:1800-5.

24. De Luca A., Bugarini R., Lepri A., et al. Coinfection with hepatitis viruses and outcome of initial antiretroviral regimens in previously naive HIV-infected subjects. Arch Intern Med 2002;162:2125-32.

25. Klein M., Lalonde R., Suissa S. The impact of hepatitis C virus coinfection on HIV progression before and after highly active antiretroviral therapy. J Acquir Immune Defic Syndr 2003;33:365-72.

26. Anderson K., Guest J., Rimland D. Hepatitis C virus coinfection increases mortality in HIV-infected patients in the highly active antiretroviral therapy era: data from the HIV Atlanta VA Cohort Study. Clin Infect Dis 2004;39:1507-13.

27. Stebbing J., Waters L., Mandalia S., et al. Hepatitis C virus infection in HIV type 1-infected individuals does not accelerated a decrease in the CD4+ cell count but does increase the likelihood of aidsdefining events. Clin Infect Dis 2005;41:906-11.

28. Weis N., Lindhardt B., Kronborg G., et al. Impact of hepatitis C virus coinfection on response to highly active antiretroviral therapy and outcome in HIV-infected individuals: a nationwide cohort study. Clin Infect Dis 2006;42:1481-7.

29. Backus L., Philipps B., Boothroyd D., et al. Effects of hepatitis C virus coinfection on survival in veterans with HIV treated with highly active antiretroviral therapy. J Acquir Immune Defic Syndr 2005;39:613-9.

30. Macías J., Melguizo I., Fernández-Rivera F.J., et al. Mortality due to liver failure and impact on survival of hepatitis virus infections in HIV-infected patients receiving potent antiretroviral therapy. Eur J Clin Microbiol Infect Dis 2002;21:775-81.

31. Antonucci G., Girardi E., Cozzi-Lepri A., et al. Role of hepatitis C virus (HCV) viremia and HCV genotype in the immune recovery from highly active antiretroviral therapy in a cohort of antiretroviralnaive HIV-infected individuals. Clin Infect Dis 2005;40:e101-9.
32. Miller M., Haley C., Koziel M., Rowley C. Impact of hepatitis C virus on immune restoration in HIV-infected patients who start highly active antiretroviral therapy: a meta-analysis. Clin Infect Dis 2005;41:713-20.

33. Sulkowski M., Moore R., Mehta S., et al. Hepatitis C and progression of HIV disease. JAMA 2002;288:199-206.

34. Rancinan C., Neau D., Savès M., et al. Is hepatitis C virus coinfection associated with survival in HIV-infected patients treated by combination antiretroviral therapy? AIDS 2002; 16:1357-62.

35. Chung R., Evans S., Yang Y., et al. Immune recovery is associated with persistent rise in hepatitis $\mathrm{C}$ virus RNA, infrequent liver test flares, and is not impaired by hepatitis $\mathrm{C}$ virus in co-infected subjects. AIDS 2002;16:1915-23.

36. Tedaldi E., Baker R., Moorman A., et al. Influence of coinfection with hepatitis $C$ virus on morbidity and mortality due to human immunodeficiency virus infection in the era of highly active antiretroviral therapy. Clin Infect Dis 2003;36:363-7.

37. Hung C., Chen M., Hsieh S., et al. Impact of chronic hepatitis C infection on outcomes of patients with an advanced stage of HIV-1 infection in an area of low prevalence of co-infection. Intern $J$ STD AIDS 2005;16:42-8.

38. Al-Harthi L., Voris J., Du W., et al. Evaluating the impact of hepatitis $\mathrm{C}$ virus (HCV) on highly active antiretroviral therapymediated immune responses in HCV/HIV-coinfected women: role of HCV on expression of primed/memory T cells. J Infect Dis 2006;193:1202-10.

39. Centers for Disease Control and Prevention, 1993. Revised classification system for HIV infection and expanded surveillance case definitions for AIDS among adolescents and adults. MMWR Morb Mortal Wkly Rep 1992;41(RR17):1-19.

40. Marins J., Barros M., Machado H., et al. Characteristics and survival of AIDS patients with hepatitis C: the Brazilian National Cohort of 1995-1996. AIDS 2005;19(Suppl 4):S27-S30.

41. Braitstein P., Justice A., Bangsberg D., et al. Hepatitis C coinfection is independently associated with decreased adherence to antiretroviral therapy in a population-based HIV cohort. AIDS 2006; 20 :323-31.

42. Bonolo P. de F., César C., Acúrcio F., et al. Non-adherence among patients initiating antiretroviral therapy: a challenge for health professionals in Brazil. AIDS 2005;19(Suppl 4):S5-S13.

43. Daar E., Lynn H., Donfield S., et al. HCV load is associated with HIV-1 disease progression in hemophiliacs. J Infect Dis 2001; 183:589-95.

44. Laskus T., Radkowski M., Piasek A., et al. HCV in lymphoid cells of patients coinfected with HIV-1: evidence of active replication in moncytes/macrophages and lymphocytes. J Infect Dis 2000; $181: 442-8$.

45. Sansonno D., Lotesoriere C., Cornacchiulo V., et al. Hepatitis C virus infection involves $\mathrm{CD} 34(+)$ hematopoietic progenitor cells in hepatitis C virus chronic carriers. Blood 1998;92:3328-37. 